\title{
Invited perspectives: challenges and future directions in improving bridge flood resilience
}

${ }^{1}$ Enrico Tubaldi, ${ }^{1}$ Christopher J. White, ${ }^{1}$ Edoardo Patelli, ${ }^{2}$ Stergios Aristoteles Mitoulis, ${ }^{3}$ Gustavo de Almeida, ${ }^{4} \mathrm{Jim}$ Brown, ${ }^{5}$ Michael Cranston, ${ }^{6}$ Martin Hardman, ${ }^{7}$ Eftychia Koursari, $5 \quad{ }^{8}$ Rob Lamb, ${ }^{5}$ Hazel McDonald, ${ }^{9}$ Richard Mathews, ${ }^{10}$ Richard Newell, ${ }^{11}$ Alonso Pizarro, ${ }^{12}$ Marta Roca, ${ }^{13}$ Daniele Zonta

${ }^{1}$ University of Strathclyde, UK

${ }^{2}$ University of Surrey, UK

$10 \quad{ }^{3}$ University of Southampton, UK

${ }^{4}$ Transport Scotland, UK

${ }^{5}$ Scottish Environment Protection Agency, UK

${ }^{6}$ Cumbria County Council, UK

${ }^{7}$ Amey, UK

$15{ }^{8}$ JBA Trust, UK and Lancaster University, UK

${ }^{9}$ Mott MacDonald, UK

${ }^{10}$ Network Rail, UK

${ }^{11}$ Universidad Diego Portales, Chile

${ }^{12}$ HR Wallingford, UK

$20{ }^{13}$ University of Trento, Italy

Correspondence to: enrico.tubaldi@strath.ac.uk

Abstract. Bridges are critical infrastructure components of road and rail transport networks. A large number of these critical assets cross or are adjacent to waterways and floodplains and are therefore exposed to flood actions such as scour, hydrodynamic loading and inundation, all of which are exacerbated by debris accumulations. These stressors are widely recognised as responsible for the vast majority of bridge failures around the world. While efforts have been made to increase the robustness of bridges to the flood hazard, many scientific and technical gaps remain. These gaps were explored during an expert workshop that took place in April 2021 with the participation of academics, consultants and decision makers operating in the United Kingdom and specialised in the fields of bridge risk assessment and management and floods. In particular, the following issues, established at different levels and scales of bridge flood resilience, were analysed: (i) characterization of the effects of floods on different bridge typologies, (ii) inaccuracy of formulae for scour depth assessment, (iii) evaluation of consequences of damage, (iv) recovery process after flood damage, (v) decision-making under uncertainty, and (vi) use of event forecasting and monitoring data for increasing the reliability of bridge flood risk estimations. These issues are discussed in this paper to inform other researchers and stakeholders worldwide, guide the directions of future research in the field, and influence policies for risk mitigation and rapid response to flood warnings, ultimately increasing bridge resilience.

Keywords: Flood risk, bridges, resilience, decision-making, scour, vulnerability, monitoring, forecasting.

\section{Introduction}

Bridges are critical infrastructure components of road and rail transport networks. A large number of these critical assets cross or are adjacent to waterways and floodplains and are therefore exposed to river flooding actions such as scour, inundation and debris impact. The hydraulic risk of bridges to flood impacts is significant globally. The 
United Kingdom is a nation where floods are of particular concern for bridge safety and operability due to the

high frequency of extreme hydrometeorological events, and the significant cascading impacts of the failure of these critical assets on wider transport networks, communities and businesses. The United Kingdom does not have a national structures database, but the number of bridges is estimated to be of the order of 160,000 in total with the Highways Agency (Middleton 2004), with about 30,000 of these crossing waterways. Network Rail also manages over 8,800 bridges in or adjacent to inland waterways (Lamb et al., 2019). While uncertain, these estimates give an idea of the high exposure of bridges to the flood hazard. The 2009 flood event in Cumbria alone resulted in 29 road bridge collapses or severe damage, $£ 34 \mathrm{~m}$ in repair and replacement costs, and significantly larger economic and societal costs (Argyroudis et al., 2019). The December 2015 floods have also resulted in further losses, amounting to approximately $£ 25 \mathrm{~m}$ direct costs. Railway bridges are also severely affected by floods, with 138 failures of these assets caused by flood-induced scour in Britain between 1846 and 2013 (Van

55 Leeuwen \& Lamb, 2014). Passenger travel disruptions due to floods were estimated to cost up to $£ 60 \mathrm{~m} / \mathrm{yr}$ for the UK railway network alone (Lamb et al., 2019), and indirect losses (e.g. impact on economic productivity) can be over one order of magnitude larger. These numbers provide a measure of the costs incurred by councils and transport operators due to floods.

The fact that bridges continue to fail demonstrates the issues and uncertainties associated with current procedures for flood risk assessment and mitigation. Moreover, the level of risk of many bridges exposed to flood effects remains largely unknown, with risk ratings still missing for many structures on secondary routes (1000 in Cumbria County alone). While efforts have been made to increase the robustness of bridges to withstand flood actions, transportation infrastructure managers face a unique challenge to prevent additional economic damage, often using maintenance budgets that are already stretched. For example, Transport Scotland spends 3 to 5 million pound per annum on flood repairs and resilience works. The projected increase in winter precipitation and river flows due to climate change is expected to increase further bridge flood risk (Jaroszweski et al., 2021). This is also due to the long service life of bridges, often exceeding the design values of 50-100 years, implying that many bridges were built long time ago, with no consideration of the impact of climate change on the intensity of flood actions.

Responding to the challenges posed by the riverine flood hazard to bridges requires quantified cost/benefit analyses of both capital maintenance/mitigation and emergency response strategies. Moreover, a joint effort of academics with different backgrounds (e.g. hydraulic and structural engineers, hydrologists, etc.), decision makers from environmental and transport agencies, consultants from regional and local authorities, and technical specialists is required. This joint effort is necessary to fully exploit the advances in the various disciplines that thus far have worked in isolation.

75 In April 2021, an online workshop organised by University of Strathclyde, in conjunction with University of Surrey and University of Southampton, brought together experts from different fields to discuss and exchange opinions, practices, experience and solutions for the mitigation of risk of bridge failure due to floods. A survey was conducted among the stakeholders in the workshop, which was subsequently analysed, and further discussed in subsequent meetings. In this paper, the outcomes of the workshop and of the subsequent surveys are summarised to inform other researchers and industry stakeholders worldwide, guide the directions of future research in the field, and influence policies for risk mitigation and rapid response to flood warnings, ultimately increasing bridge resilience in the United Kingdom and the rest of the world. Section 2 illustrates known challenges and knowledge 
gaps in both science and current risk management procedures. Section 3 provides general recommendations for future research in the field and for improving current emergency and risk management procedures.

85

\section{Challenges and knowledge gaps}

\subsection{Flood actions on bridges and hydraulic modelling}

Although scour is the most critical hydraulic action for bridges, other actions need to be considered in evaluating bridge flood risk, the most important being buoyancy (i.e. uplift forces exerted on submerged bridge components), hydrodynamic (drag) forces, impact forces exerted by large floating objects (e.g. vehicles). All of these mechanisms are exacerbated by debris (e.g. wood) that accumulate around piers and decks during floods (Bridge et al., 2017, Mondoro and Frangopol, 2018; Cantero-Chinchilla and de Almeida, 2021). CIRIA Manual and the latest update (Bridge et al., 2017, Kitchen et al., 2021) provide an exhaustive state of knowledge on the assessment of debris impact and hydrodynamic forces on bridges, drawing on standards, guidance and research from various countries. It is worth to note that existing design guidelines for the assessment of hydrodynamic forces are nonconservative (i.e. do not provide an appropriate margin of safety) in some regimes, as demonstrated through an extensive experimental and numerical campaign by Oudenbroek et al. (2018). These results have shown that important underestimation of forces may be obtained for cases in which free surface effects are important, for deeply submerged bridge decks, or for high blockage ratios. This and other recent studies have also highlighted that hydrodynamic forces can be significantly exacerbated by debris causing damming and build-up of water (also known as afflux). On a more practical level, transport agencies and operators stress the need for developing and/or reviewing the effectiveness of technical solutions for tackling the problem of mitigation of hydrodynamic forces for bridges at risk. Possible solutions could be aimed at reducing the hazard, by enlarging the cross-section area of the bridge, or by building a flood relief channel. However, both of these solutions can be expensive, disruptive and have undesired morphodynamic consequences. Alternative solutions could be aimed at reducing the bridge vulnerability, by holding down the bridge deck onto the piers and the foundations in order to counteract the uplift action of water.

The characterization of the joint effects of the flood actions is complicated, and laboratory and numerical studies often focus on one or few specific actions (Ebrahimi et al., 2017). Experimental tests of the actual process of bridge failure have to address the challenge of scaling (Oudenbroek, 2018), while computational analysis must

110 overcome the issues related to modelling sediment transport and scour under complex, real-world conditions. Field measurements of all these simultaneous actions during floods are lacking, and studies deploying multiple sensors for monitoring both the bridge structure and the river flow are scarce (e.g. Crotti and Cigada, 2019). Moreover, typical models used for evaluating the hydraulic actions of interest often introduce some simplifications in the analyses, the limitations and impact of which on the results are not fully appreciated by end users. One example is the use of one-dimensional hydraulic modelling, which may not be suitable in the vast majority of realworld cases, where substantial gradients in the flow velocities are observed. In these cases, more accurate estimates of flood actions should be obtained resorting to two (or three)-dimensional modelling (e.g. Lai and Greimann, 2010). 


\subsection{Formulae for scour depth assessment}

This subsection summarises the most critical issues and knowledge gaps in evaluation of scour at bridges that have emerged during the workshop. For a more detailed and exhaustive review of the problem, reference can be made to the CIRIA manual and subsequent updates (Kirby et al., 2015, Kitchen et al., 2021), and to the recent work of Pizarro et al. (2020).

Typically, formulae for scour evaluation are based on lab flume trials at small scale and use empirical relations between scour depth and parameters that can be controlled and measured in a flume, rather than seeking to establish the effect of parameters on the flow-field and the resistance of the bed sediment to erosion. While a wide range of conditions can be tested in flume experiments, very often tests adopt several simplifications of the mechanisms operating at full-scale in natural rivers, e.g. steady or quasi-steady hydraulic conditions, uniform sediment sizes, and simple bridge and channel geometries. Whilst the flow-field around bluff, surface piercing obstacles is complex, there is a need for a better understanding of the physics of local scouring around structures, and for developing general predictive models more strongly rooted on physical, rather than empirical grounds, as pointed out in Manes \& Brocchini (2015).

Many empirical scour formulas are available that provide estimates of the equilibrium scour depth, which can be largely defined as the maximum scour depth that could be attained under a steady flow regime impinging the pier for a duration tending to infinity. Well-known equilibrium scour formulas are the Hydraulic Engineering Circular No. 18 (HEC-18, Richardson and Davis, 2001) and the Florida Department of Transportation (FDOT, Sheppard et al., 2014), which are widely used in the U.S.A. The scour manual by CIRIA (Kirby et al. 2015) suggests the use of the equation developed by Breusers (1977), which has later been further investigated (Melville and

140 Sutherland, 1988; Breusers and Raudkivi, 1991; Melville and Coleman, 2000). There is also a significant number of studies within the scientific literature comparing the accuracy of the formulas based on laboratory data and field data (see, e.g., Johnson et al., 2015; Liang et al., 2019; Park et al., 2017; Sheppard et al., 2014; Johnson et al., 2015; Qi et al., 2018; Wang et al., 2017; Shahriar et al., 2021). In general, application of common equilibrium scour formula results in significant overestimations of scour depths compared to field observations. This can be due to a number of reasons, including on site sediment non-uniformity, equilibrium scour depth being not attained, scaling effects inherent to flume experiments, complex pier and channel geometries compared to an idealized laboratory test, but also due to measurement inaccuracies. In addition, scour measurements are typically conducted after the flood event recedes, when the scour hole might have been refilled with sediment under live bed conditions (thus masking the maximum depth reached during the peak flow).

150 Methods for time-dependent scour evaluations have been developed that can be applied for the assessment of scour under single (or multiple) flood events, opening the avenues for more accurate scour estimates. Additionally, and worthy of mentioning is the recent contributions for time-dependent scour modelling under non-stationary conditions. Among them, Pizarro et al. (2017a,b) and Link et al. (2017) proposed the dimensionless effective flow work, $\mathrm{W}^{*}$, and the dimensionless flow work (DFW) model to be used under flood waves. Additionally, Link et

155 al. (2020) proposed an extension of the model to consider the counter effects of erosion and deposition within the scour hole, which are typical of live-bed conditions.

The effects of debris on scour evolution are also a topic of extreme interest that has been subject of significant research efforts in the last decades. Cantero-Chinchilla et al. (2021) lists the most important studies on the topic 
and presents an assessment of the influence of flow intensity, blockage area ratio, and depth ratio on the development of local scour with flow-dependent debris accumulation. Debris accumulations can increase local scour depths by a factor of two or more compared to local scour depth without accumulations. The increase in scour depth that results from debris accumulations depends critically on the characteristics of debris accumulations (e.g. size and shape, which mainly determine their influence on scour) that will form at a given location, which is difficult to predict. Experiments by Panici and de Almeida (2018, 2020, Figure 1) provide methods to estimate the maximum dimensions possibly formed under given flow and debris conditions. However, additional experimental research is needed to extend the range of applicability of existing methods and approaches, and to characterize the likelihood of accumulation of debris at bridge piers.

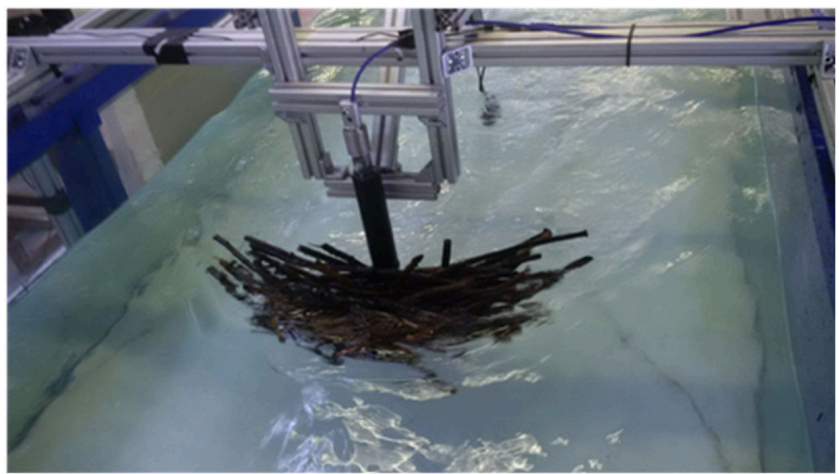

Figure 1: Debris accumulation formed in the laboratory (Panici and de Almeida, 2018).

Another important issue that requires further investigation regards the prediction of the geometry of scour holes (and how it develops over time) for complex bridge pier geometries. It is usually assumed that the shape of scour hole is indeed independent of the flow conditions and that it can be approximated by an inverted cone/pyramid with the upstream slope corresponding to the sediment's angle of repose, but these assumptions work well only for simple geometries such as cylindrical piers, as proven by Chreties et al. (2013), local scour conditions, and also for a flow direction perpendicular to the bridge longitudinal axis. The load bearing capacity of foundations and more in general the bridge response to scour and collapse mechanisms are significantly affected by the scour hole geometry (Maddison 2012). The numerical studies of Tubaldi et al. (2017) and Scozzese et al. (2019) have shown how important it is to consider this when predicting or simulating the collapse behaviour of masonry arch bridges, exhibiting major damage in correspondence of their upstream side, where the scour hole is usually deeper (see Figure 2 and Figure 3). Thus, more research in this field is required in order to have an insight into the shape of scour holes that could develop at bridge foundations and under different flow conditions (e.g. angle of attack of flow). 


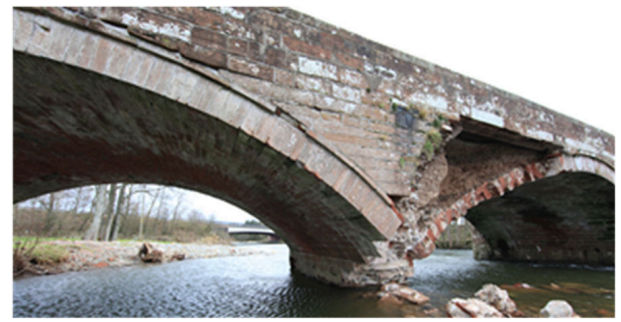

(a)

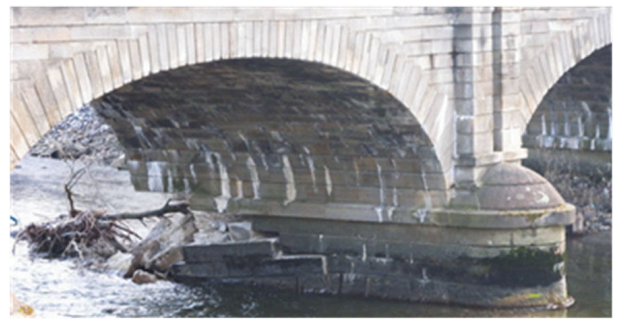

(b)

Figure 2. Damage of Brougham Old Bridge (a) and of Calva bridge (b), typical of many masonry arch bridges subjected to scour (Source: Cumbria Council County for (a) and Bill Harvey for (b)).

\subsection{Vulnerability of various bridge typologies}

The evaluation of the vulnerability of bridges to floods has received little attention compared to other hazards such as earthquakes. This is mainly due to a combination of factors, including the complexity of the physical processes and the many variables involved in the performance assessment (Tanasic et al. 2017), and the difficulties, costs and uncertainties associated with measurements of the consequences of bridge failure (Lamb et al. 2017). As a result of this, robust and validated methodologies for flood fragility and vulnerability assessment of bridges are scarce, although some attempts to develop such methodologies were recently made, with the aid of expert judgement or numerical modelling. Lamb et al. (2017) put forward a formal elicitation process to identify bridge vulnerability factors, summarizing the current knowledge of the problem of scour from various experts in the field. Not surprisingly, the foundation depth, type and the level of uncertainty in the estimation of these quantities emerged as the most important factors that should be considered when assessing bridge flood vulnerability and risk. However, the bridge type was ranked only 16th as vulnerability factor, which is quite interesting given the very different behaviour and capacity to withstand scour of a masonry arch bridge compared to a bridge with a multi-span simply supported deck. In general, modern steel and reinforced concrete structures, often founded on piles, should have been designed to withstand hydrodynamic forces and scour. They should also retain adequate vertical bearing capacity even under significant exposure of the total pile depth, provided the piles have a moment connection with the pile cap. On the other hand, masonry arch bridges are the most vulnerable to scour, due to the combination of their high stiffness and the fact that they are often built on shallow footings resting on the riverbed.

Among the numerical approaches investigating bridge vulnerability, worth mentioning are the works of Zampieri et al. (2017), Tubaldi et al. (2018), and Scozzese et al. (2019) on the simulation of the collapse mechanisms of masonry arch bridges with shallow foundations subjected to scour. Hydrodynamic forces are generally not a concern for these bridges unless the water level reaches the arch springing. In this case, there is also a potentially significant risk of debris accumulating at the bridge (Schmocker and Hager, 2011), resulting in further flow constriction, increased hydrodynamic forces, and higher scour rates and depths. If the water level exceeds the level of the arch soffit, the available hydraulic section is significantly constricted, not only in the horizontal but also in the vertical direction. Under these conditions, hydrodynamic forces become very significant and buoyancy forces may result in significant reduction of the vertical load carrying capacity (Hulet et al. 2006). Moreover, the vertical flow contraction exacerbates scour. More advanced and comprehensive numerical models and 
methodologies need to be developed to assess the fragility of masonry arch bridges to the various flood actions. These models should account for the complex three-dimensional nature of the problem, as highlighted by studies investigating numerically the collapse mechanisms of some bridges (see e.g. Tubaldi et al., 2018; Wiggins et al., 2018; Scozzese et al., 2019).

Tanasic et al. (2013) developed scour vulnerability curves for a reinforced concrete bridge with a four-span continuous bridge, considering two failure modes, one related to the deformation capacity of the superstructure and the other to the bearing capacity of the soil-foundation system. Kim et al. (2017) also developed a methodology for flood fragility analysis of a multispan bridge considering multiple failure modes, including exceedance of pier or pile ductility capacity, pier rebar rupture, pile rupture, and deck loss. A recent study by Argyroudis et al. (2021) has focused on the vulnerability of prestressed concrete bridges to flood actions (scour, debris accumulation and hydrodynamic forces). Both integral bridges, where the abutment and piers are monolithically connected to the deck, and bridges with bearings were examined. Integral bridges were found to be more vulnerable to scour, since bearing flexibility provides some tolerance to scour-induced settlements. In addition, different structural components were found to be critical in different bridge types, e.g. the deck was found to be the most vulnerable structural component in integral bridges, and the bearings in the others, with settlements and hydrodynamic forces leading to serious damage of these devices. This shows that a substantial effort is needed to quantify the risk and the sequence of mechanisms that lead to the various bridge damage modes during floods.

Another strategy for vulnerability assessment is to infer fragility functions empirically from real-world (or perhaps experimental) loading and failure observations. In earthquake engineering, there are established statistical approaches for fragility assessment (Porter, 2015), the limit states and critical failure mechanisms of the resisting components are well defined, and there may be many observations of the limit state being exceeded within a single event; this is not the case for bridges and floods. Lamb et al. (2019) demonstrated the application of statistical inference to estimate a fragility function for railway bridge failures in Britain using observations of historical failure events, which were integrated within a whole-network economic risk analysis. The historical data could only be interpreted in this way by adopting a broad definition of bridge failure and expressing the intensity of the flood through its return period, a non-physical measure.

One major problem in bridge vulnerability assessment is the identification of a practical and representative intensity measure (IM) for quantifying the flood hazard and the vulnerability. For example, in Argyroudis et al. (2021) the maximum scour depth was used as IM, but scour can be a cumulative phenomenon, and thus there is only a mild correlation between scour depth and other actions (e.g. drag forces) during a flood. According to the outcomes of the study of Lamb et al. (2017), an appropriate intensity measure for the expression of bridge fragilities could be the flood return period itself. This could be helpful to summarize in a single scalar quantity the joint effects of different flood actions, but would not allow to fully decouple the hazard assessment from the bridge fragility evaluation. For example, one could consider the case of a bridge assumed to collapse when the water level reaches the deck. This bridge, placed in two rivers, one characterized by a significant flood hazard and the other by a low flood hazard, would present different probabilities of collapse (i.e., different vulnerabilities), since the probability of the water level reaching the deck would be higher in the case of significant flood hazard. This criticism of the use of the return period is ameliorated by the fact that modern bridges and scour protection 
255 may respect design standards based on a specified flood return period, whilst older bridges are likely to embody some intuition about the local hazard, such that bridges will tend to be more resilient in locations that present a greater flood hazard. However, an underlying physical IM cannot be expected to scale linearly with the flood return period, so the increase in physical loading between, say, a 25-year and 100-year flood event could differ between locations, depending on their physical characteristics.

260 In addition, the return period typically only characterises the peak discharge, and not the duration of the event, which may be needed for the critical scour depth to develop. Thus, further studies are necessary in order to identify the optimal intensity measures for representing the flood hazard and quantifying the flood fragility for different bridge types. Alternatively, vector-valued IMs (Tubaldi et al. 2017) could be considered for describing the flood hazard, e.g. combining the flow height/velocity, representing the hydrostatic and hydrodynamic force, and the maximum scour depth, representing the scour action. Fragility surfaces could be used for quantifying the probability of bridge failure conditional on multiple intensity measures, whereas state-dependent fragilities would be needed to account for the existing scour depth resulting from the action of past flood events. Further studies are also needed to identify the engineering demand parameters and limit states for the components of bridge types other than concrete ones.

270 Finally, another important aspect in the development of vulnerability curves for bridges is the characterization of the costs and consequences due to bridge performance degradation. These should include the direct consequences of structural damage (e.g. repair costs required to return the damaged bridge to its original state, as well as injuries, life losses, etc), and indirect consequences (e.g. service restrictions, additional travel time and travel distance costs for network road users). With regards to direct costs, worth to mention is the record prepared by Cumbria County

275 Council of scour depths, bridge damages and repair costs resulting from the December 2015 floods in Cumbria for 350 sites. This record constitutes a unique opportunity to carry out a monetised assessment of the risks from extreme flooding. Combining this record with hind-cast flows for the storm events can provide a data set that can be mined to yield correlations between the cost of damage and all the site and flow variables. Some preliminary analyses performed by Mott MacDonald have shown that two thirds of the repair costs could have been avoided had it been feasible to identify and protect the most vulnerable $11 \%$ of the damaged bridges.

With regards to indirect consequences, while there are many tools available to assess the impact of bridge closure on the traffic flow in a network (see e.g. Liu et al. 2018, Lamb et al. 2019), there is a current lack of data on the high repair costs and downtimes associated with various bridge failure modes (Figure 3). Thus, recourse to expert elicitation appears unavoidable for characterising this, as discussed more in detail in the next subsection. 


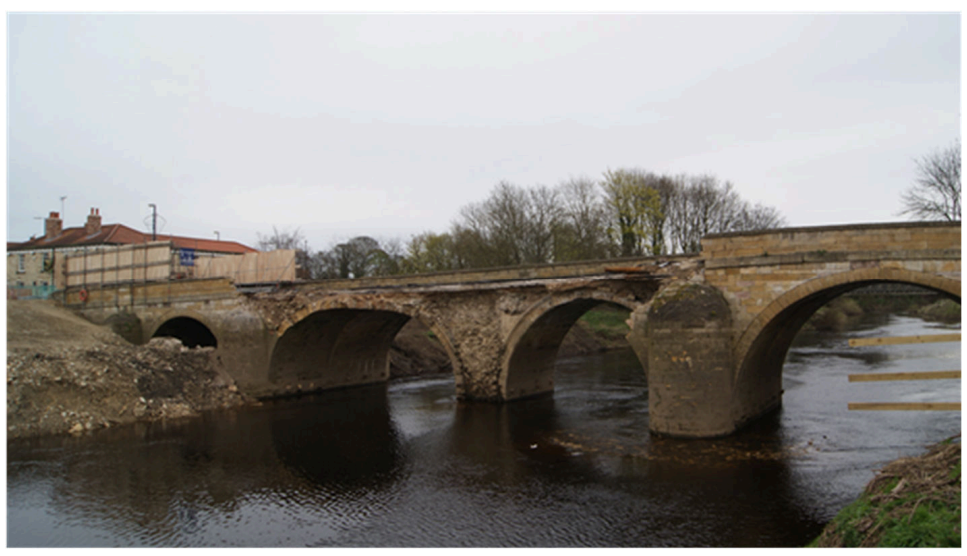

Figure 3. Tadcaster bridge, damaged by Storm Eva in 2015, repaired and reopened to traffic 13 months after. Bridge closure resulted in 9-mile detour of 20 minutes to reach the other side. Source: https://commons.wikimedia.org/wiki/File:Tadcaster_Bridge_closed_following_last_years_damage_(10th_April_2016) _005.JPG

\subsection{Quantification of restoration and reinstatement models}

The ability to quickly restore bridges whose stability or functionality has been impaired by floods is essential to improve the resilience of transport infrastructure. It is perhaps the most pressing challenge for road and railway operators who manage bridges. The challenge is related to the prioritisation of mitigation measures, due to limited resources, prior and/or after extreme floods, and the uncertainties associated to future events and the bridge performance.

The work of Mitoulis et al. (2021) summarises the main tasks for bridge recovery after floods. The paper is the summary of an elicitation survey the results of which were made available in Mitoulis and Argyroudis (2021). In this paper, bridge recovery is split into structural restoration and functionality reinstatement. Restoration includes all structural measures to tackle structural damage, whilst reinstatement is related to non-structural loss caused by, e.g. debris accumulation and or water on the bridge deck. The study highlights several findings and a number of inadequacies and challenges for the future. The first finding is non-engineering, and related to the reluctance of operators to identify the urgent need for bridge and transport network recovery models. Moreover, shorttermism and short-term responsibilities in bridge maintenance leave little space and funds for long-term investment, e.g. for adaptation to climate change and socio-economic change.

The second outcome of the elicitation survey was that restoration tasks have (small or large) spatio-temporal dependencies, as well as logical dependencies and are similar to different bridges. The duration of each restoration task depends on the extent of damage. Hence, the same restoration task (e.g. FRP strengthening of the deck) would be more time-consuming when the damage is more extensive. There was a great discrepancy in the experts' opinions and follow-up meetings were required to obtain more information with regard to the duration of restoration tasks. It was also established that there is a strong correlation between restoration (capacity) and reinstatement (traffic/functionality) times. Generally, operators are striving to reinstate functionality as quickly as possible and open the bridge to traffic, rather than just retrofit the bridge and restore its structural capacity. 
Reinstatement is important for the operator as the aim is to reduce the indirect costs due to bridge closures.

\subsection{Current flood risk management procedures}

In the UK, the document BD 97/12 (Highway Agency, 2012) and the EX2502 Procedure (HR Wallingford, 1993) are employed respectively by the highway authorities (Highways England, Transport Scotland) and railway authorities (Network Rail) and by their respective operating companies for assessing and managing the flood risk of bridges. Transport Scotland has also introduced a Scour Management Strategy and Flood Emergency Plan which documents their response to scour inspection, assessment, and flood mitigation measures. Alternative procedures for the risk assessment of bridge exposed to floods have also been proposed by other organisations in the UK. CIRIA has produced a comprehensive manual on scour at bridges (Kirby et al, 2015) which covers the scour risk management process, from the identification of bridge elements exposed to hydraulic action, to the prioritisation of scour-susceptible structures and selection of options. The manual has been recently updated with the Supplementary Guide, CIRIA SP171 (Kitchen et al, 2021) to include the latest knowledge from asset owners, industry practitioners and academics. Following the 2015 event, Mott MacDonald and Cumbria County Council jointly developed a warning system for damaged bridges, using the live feeds from Environment Agency river level gauges as a surrogate for river flow (Mathews and Hardman 2017). This system uses records of damage in December 2015 and a percentage of the associated record level as a predictor of further damage. This system proved cost effective for the management of damaged structures, though it falls short of the requirements for a true risk-based system.

These procedures are mainly focused on the scour hazard, which poses the major risk to their assets. The estimate of the scour depth under a hypothetical 200 year return period is used to categorise the bridge assets and prioritize risk mitigation interventions. These estimates often result in excessive and unrealistic levels of the scour depth, which should not be interpreted as expected levels of scour under a flood scenario. The $20 \%$ increase (uplift) applied to the design peak flow to account for climate change effects does not account for any particular time horizon or regional differences, which vary between $+4 \%$ and $+52 \%$ in current guidance for England (central estimates, 2080s, Environment Agency, 2021), thus resulting in further bias and uncertainty in risk estimation. Information on the bridge vulnerability and potential losses (e.g. cost of repairs, traffic disruption, and the financial consequences of death and injury) are disregarded or taken into account in a simplified way by means of some heuristic coefficients increasing the risk rating. Moreover, priorities based on one return period do not consider the cumulative risk arising from less intense, but more frequent events (Tubaldi et al., 2017). This is an often overlooked, important aspect, considering that the estimated return periods of the floods that lead to failure of many bridges in the UK that failed in the last 150 years were below 100 years (Van Leeuwen and Lamb, 2014). Flood emergency management and decisions concerning costly bridge closures are based on the water level at the bridge exceeding some limits (e.g. flood level markers corresponding to a 200 year return period flood, see e.g. Transport Scotland's Scour Management Strategy and Flood Emergency Plan), which are often difficult to correlate to the actual risk of bridge failure. An alternative to methods that focus on a single return period is based on the integration of damages caused by events with different probabilities (expected annual damage), which may 
provide a more comprehensive picture of the risk profile, although it also disregards the cumulative effect of sequences of events (Tubaldi et al., 2017).

Hence, it can be concluded that the decision-making by transport agencies is not based on the explicit evaluation of the flood risk of bridges and of the expected losses arising due to bridge failure, and disregards many of the uncertainties inherent to the hazard, the data and the models used for risk assessment (see e.g. Dikanski et al. 2018, Pizarro and Tubaldi 2019, Bento et al. 2020).

During the workshop, another important limitation of current risk management approaches emerged, i.e. the fact that they rely significantly on visual inspections (Moore et al., 2001; Jeong et al., 2018). These include underwater bridge inspections, and are carried out by divers at regular intervals to check the state of any bridge component but also during and/or following flood events (e.g. reactive structures safety inspections and special inspections). Visual inspections are characterized by many drawbacks. They can be affected by human error, subjectivity of the inspector, can be expensive and time-consuming. Moreover, underwater inspections cannot be carried during heavy flood events and can be conducted only after floods have receded, when scour holes may have been refilled, thus hiding the real hazard to which the structure has been exposed.

The issues outlined above, combined with the difficulties in obtaining information regarding the typology, geometry and state of bridge components (e.g. bridge foundation type, depth, etc.), may severely limit our ability to the identify bridges at higher risk of failure. Thus, current risk management approaches could be improved by adding a more explicit assessment of the actual bridge risk with due consideration of various sources of uncertainty affecting the problem and of the consequences of bridge damage. HR Wallingford (Roca and Whitehouse 2012) has also developed a fully probabilistic approach for scour risk assessment that could be used to quantify the probability of bridge failure by accounting for the uncertain structural response through bridge-specific scour fragility curves. A similar approach was advocated by Tubaldi et al. (2017) and Pregnolato (2019). Sasidharan et al. (2021) also developed a conceptual risk-informed approach for bridge scour management that considers the direct and indirect consequences associated with closure or failure of bridges due to scour within the decision making. This framework could be used to identify cost-effective solutions for bridge scour management and risk mitigation.

\subsection{Use of inspection, monitoring and forecast data}

Bridges and riverbeds are periodically assessed within general and principal inspections, and via reactive inspections following flood events. These inspections may provide some information on the temporal evolution of scour and of the bridge state, but it is only by resorting to environmental or structural health monitoring (SHM) measurements that damage can be anticipated or assessed in real time. Monitoring data can significantly contribute to increasing the resilience of critical infrastructure under a wide range of hazards by providing information useful for disaster prevention, disaster mitigation, and disaster recovery (Honfi and Lange, 2015; Achillopoulou et al., 2020). In particular, monitoring data can be valuable for achieving a better understanding of the behaviour of critical infrastructure assets under extreme events, and for model calibration and updating at any level, from hydrological and hydraulic (Beven et al., 2005; Montanari et al., 2009; Briaud et al., 2014) to structural (e.g., Prendergast et al., 2018). 
Moreover, SHM improves the knowledge of the current state of the asset, and provides bridge managers with useful information for prioritizing retrofit and risk reduction interventions. It can also be useful for bridge state assessment before, during or after extreme events (Maroni 2020). Obtaining information regarding the integrity of the structure in near real time has positive effects for the rapid response to these events and the recovery, starting from the rescue operations. Thus, it is evident that SHM data can be useful in overcoming some of the limitations of visual inspections, reducing their frequency and increasing their reliability with complementary information.

A wide range of sensors and sensing techniques has been developed in recent years to support bridge flood risk assessment (see e.g. Prendergast and Gavin, 2014; Maroni et al., 2020; Tubaldi et al., 2020; Achillopoulou et al., 2020, which are mainly focused on the scour problem). However, current practices for bridge flood risk management have not benefited from the advancements in the fields of flood and bridge monitoring, due to reasons such as the high capital and installation costs of sensors, the difficulty in post-processing the large datasets they produce, the challenges in interpreting sensor observations, and a lack of a rigorous quantification of the benefits they bring in terms of better-informed decision making in bridge risk management. One way to overcome the cost limitation is to install monitoring systems only at critical locations, by extending the information gained at these locations to the other assets through the use of Bayesian Networks. Criticality could be defined operationally, by asset owners, or take account of wider analysis of the number of users who may be directly or indirectly disrupted by the failure of physically interdependent infrastructures (see Thacker et al., 2017). This approach has been developed originally by Maroni et al. (2020) considering the problem of scour risk assessment, using data from scour probes (Figure 4a) and gauging stations. It has been subsequently extended to include observations from inclinometers or GPS receivers (Tubaldi et al., 2021), which may also be useful for assessing the bridge state. A further extension of the developed Bayesian Networks is required to allow merging information with different temporal resolutions, such as bathymetry observations obtained during inspections (every few years) and continuous measurements of flow height or surface velocity. Such an extension would also allow accounting for the results of inspections. Methodologies are also needed for using sensor data to support decision-making and for quantifying the benefit, in terms of better-informed decision making, of the information provided by sensors. Concepts such as the value-of-information and the reduction of relative entropy could be used for this purpose (Giordano et al., 2020, Tubaldi et al., 2021), whereas theories such as expected utility (Cappello et al., 2016) and multi-criteria decision making (Triantaphyllou, 2020) could help to set sensor reading thresholds and configure alert settings.

Accurate monitoring of scour depth during flood events is critical for emergency decision-making (closure and opening of bridges), but also to enable a more accurate, data-rich risk assessment strategy to be developed. Remote controlled survey boats (Figure 4b) may provide a relatively easy way to inspect critical assets during flood events. Based on the workshop and subsequent surveys, one field where more research work is required is the evaluation of the accuracy and the benefit of various techniques for the evaluation of the unknown foundation depth. This parameter, controlling the risk rating of bridges with shallow foundations, is often characterized by significant uncertainty. Although some non-destructive techniques have been proposed and are employed for the evaluation of bridge foundation depths (see e.g. Hossain et al., 2013; Tucker et al., 2015), they are not always accurate and reliable, and recourse to coring is often unavoidable. However, it is not infrequent that bridges classified at high risk of scour due to an initial conservative assumption of the foundation depth (e.g. between $0.3 \mathrm{~m}$ and $1 \mathrm{~m}$ for 
masonry bridges) are then considered at low risk level following a survey of the foundations. In many circumstances, it is advisable to spend more in accurate bathymetric surveys and extensive coring at multiple locations if this permits to avoid installing expensive protection measures. This is for example the case when stones and material needed for riprap are not available on site, thus resulting in high transportation costs. On this regard, Network Rail has documented the case of a bridge where recourse to surveys of the riverbed has avoided deployment of scour protection measures.

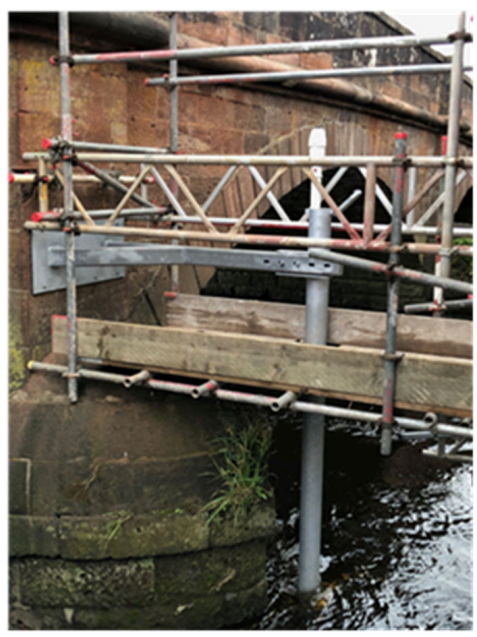

(a)

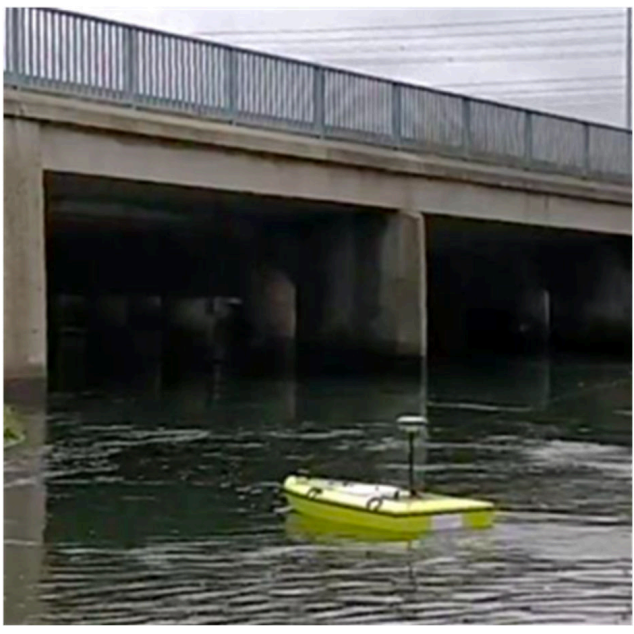

(b)

Figure 4. a) Probe for continuous monitoring of total scour at a pier of the A76 200 bridge over the River Nith in New Cumnock (Maroni et al. 2020); b) Surveying remote controlled boat equipped with sonar, acoustic doppler velocity profilers, RTK-GPS and other motion sensors (developed at University of Southampton).

Flood forecasting and monitoring sensors and data are vital for the future development of improved flood warning and risk monitoring systems. Impact-based forecasts - conveying information about the impact of the flood, taking into consideration vulnerability and exposure factors - for risk identification and communication have been shown to increase trust in warning systems, leading to more effective resilience building (Merz et al., 2020). Increasing the ability of the hydrological community to engage with the future development of impact-based forecasts (and to use machine learning and artificial intelligence tools to build and augment impact models (Wagenaar et al., 2020)) would help to further accelerate this process. For example, rainfall data combined with rainfall-runoff modelling for watersheds of critical bridges can be used to provide actionable alerts that could inform emergency management and trigger bridge closures (e.g. Cranston and Tavendale, 2012). Other aspects of flood forecasting, such as surface water flood forecasting (e.g. Speight et al., 2021), and forecasts on longer lead times can also be explored to assess their potential utility and application for bridge resilience. For example, the next generation of forecasts on larger spatial scales, such as the European-wide EFAS flood forecasting system (Wetterhall and Di Giuseppe, 2018), or the global subseasonal-to-seasonal meteorological predictions (White et al., 2017), can be employed to extend existing flood forecast and warning capabilities. These approaches pose some challenges due to the large uncertainties in the predicted rainfall at longer lead-times (or even over a few hours for surface water 
flooding after intense convective rain storms, Birch et al., 2021), significantly amplified by rainfall-runoff models (see e.g. Komma et al., 2007; Yu et al. 2016).

River level and velocity monitoring systems could be used for real-time risk monitoring. In this regard, it is worth noting that many wireless low-cost techniques have been recently developed that could be employed to gain useful information on the river hydraulic properties (e.g. Rivertrack sensors for measuring water level (Rivertrack 2021) or cameras for particle image velocimetry (see e.g. Dal Sasso et al., 2021a). This is particularly relevant for ungauged river locations. Satellite imagery, aerial photography and UAVs technology (Figure 5) can also be very useful for monitoring morphological changes in rivers (Akay et al., 2021; Dal Sasso et al., 2021b) that may potentially lead to increased risk for bridges (see e.g. Koursari and Wallace, 2019). They can be important when there are accessibility issues (e.g. roads closed/destroyed) following flood damage. In general, it would be preferable to deploy sensors that do not need to be installed underwater, since obtaining permits from environmental agencies to work in watercourses can be problematic. Recent advancements in terms of imagevelocimetry for fluvial monitoring could be adapted to give additional information on the hydraulic properties of the flow at bridges. This information could then be used to feed scour models for forecasting or assessing in real (or near-real) time the risk of bridge failure due to hydraulic actions. Some successful examples of the use of remote sensing techniques to recover flow velocities and river discharge are from Le Coz et al. (2010), Pizarro et al. (2020), Eltner (2021), Bandini et al. (2021), and Fulton (2020).

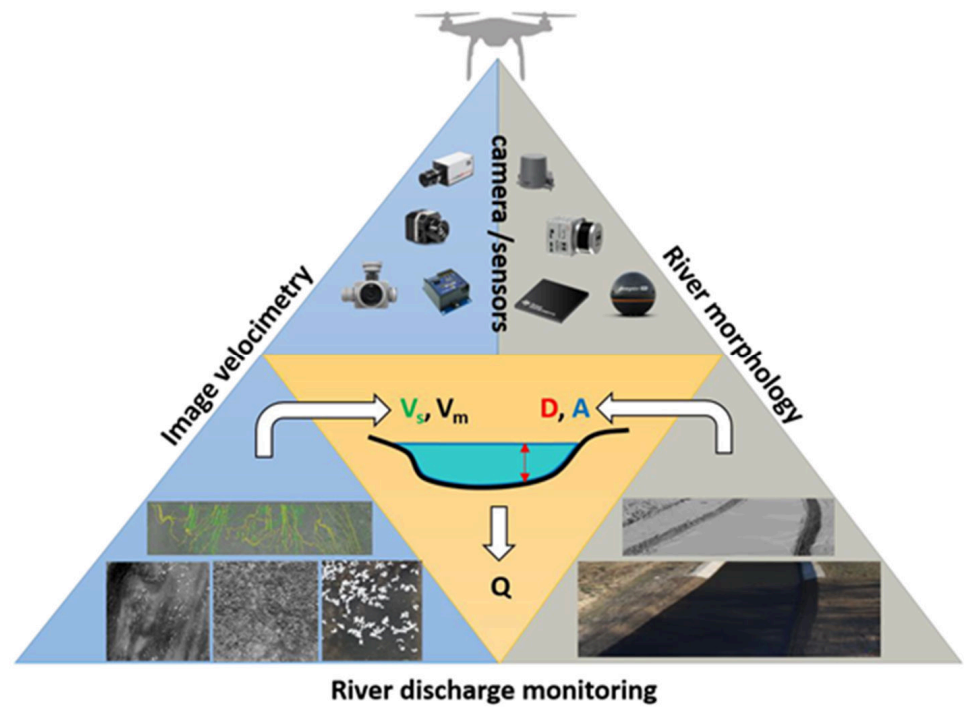

Figure 5. Adapted from Dal Sasso et al. (2021b). Potential in the use of UAS for river monitoring combining river morphological and surface velocity estimations. The combinations of different sensors (e.g., RGB or TIR camera, LiDAR, eco-sounder, etc.) may help to measure flow at bridges in different fields and flow conditions.

\section{Conclusions and future directions}

The workshop and subsequent meetings have highlighted many areas where further efforts and research is needed in order to improve bridge resilience to floods. Table 1 provides a list of the most important actions that should be taken for achieving this challenging goal. This list has been prepared taking into account the limited resources available to bridge owners and managers. 
480 These actions will help to refine and improve further the already advanced tools for modelling and monitoring of floods and bridges, and for identifying the optimal decisions to take in both emergency and long-term flood risk management of bridges. This can help shift the flood risk assessment paradigm from manual and inaccurate diagnoses that rely heavily on costly and potentially inaccurate visual inspections, towards impact-based forecasting and near real-time evaluations of the risk supported by digital twinning technologies (Ye et al. 2019). It can also help to better define strategies to tackle the uncertain effects of climate change and socio-economic growth.

In the near future, information from physical modelling and real-time data from heterogeneous sensors could be incorporated into the same platform to develop virtual representations of physical infrastructure assets that can be used to track the time-dependent state of the asset, with applications for both health diagnosis and prognosis (i.e. prediction of damage and functionality loss due to future events). Enforcing the Digital Twin concept in the context of flood risk assessment of bridges would provide infrastructure managers with valuable information, helping them to take optimal actions for both emergency response and long-term risk assessment and management. This could ultimately improve current risk management procedures which are overly simplistic and/or risky, and have not benefited from recent progresses in sensing and information technologies. The urgent need for this is widely acknowledged by the academics, bridge stakeholders and industry specialists that participated in the workshop on bridge flood risk assessment and management and contributed to this paper. 
Table 1. List of actions and next steps for improving bridge resilience to flooding.

\begin{tabular}{|c|c|}
\hline Domain & Description \\
\hline \multirow{4}{*}{$\begin{array}{l}\text { Hazard } \\
\text { assessment and } \\
\text { mitigation }\end{array}$} & -Characterization of the likelihood of accumulation of debris at bridge piers. \\
\hline & $\begin{array}{l}\text {-Critical review and evaluation of the effectiveness of technical solutions for mitigating } \\
\text { hydrodynamic forces for bridges at risk of inundation. }\end{array}$ \\
\hline & $\begin{array}{l}\text { - Extension of current flood forecast and warning capabilities to longer lead times and uncertainty } \\
\text { characterization. }\end{array}$ \\
\hline & - More accurate modelling of the impact of climate change on frequency and intensity of flooding. \\
\hline \multirow{4}{*}{$\begin{array}{l}\text { Hydraulic actions } \\
\text { modelling }\end{array}$} & $\begin{array}{l}\text {-Additional field research, data collection and analyses also needed to characterize the interrelated } \\
\text { flood actions and validate models. }\end{array}$ \\
\hline & $\begin{array}{l}\text { - Characterization of the temporal evolution of scour under the influence of time-varying } \\
\text { intervening variables characteristic of flow and debris, with further experiments extending the } \\
\text { range of applicability of developed approaches. }\end{array}$ \\
\hline & $\begin{array}{l}\text {-More research on the effect of bridge pier and foundation geometries on the development of scour } \\
\text { and on the scour hole shape. }\end{array}$ \\
\hline & $\begin{array}{l}\text {-Development of models for establishing the relationships between measured river parameters } \\
\text { (flow height, surface water velocity) and parameters controlling scour and hydraulic actions (e.g. } \\
\text { depth averaged velocity). }\end{array}$ \\
\hline \multirow{3}{*}{$\begin{array}{l}\text { Vulnerability } \\
\text { assessment and } \\
\text { reduction }\end{array}$} & $\begin{array}{l}\text { - Identification of optimal intensity measures to be used in fragility analyses for describing the } \\
\text { joint effect of various flood actions on bridges. }\end{array}$ \\
\hline & $\begin{array}{l}\text { - Definition of a methodology for evaluating the vulnerability of various bridge types to concurrent } \\
\text { flood-induced actions, accounting for cumulative effects (e.g. scour accumulated in previous } \\
\text { floods) and the effects of debris through advanced modelling of water-soil-bridge assets. }\end{array}$ \\
\hline & $\begin{array}{l}\text { - Cost-benefit analysis of alternative solutions for mitigating the risk of bridge deck unseating and } \\
\text { uplift. }\end{array}$ \\
\hline \multirow[t]{2}{*}{ Risk management } & $\begin{array}{l}\text { - Development of decision support tools to aid bridge managers to identify optimal actions for } \\
\text { emergency/long-term flood risk management (including restoration and/or adaptation measures to } \\
\text { climate change). These should take into account the bridge fragility and the consequences of bridge } \\
\text { failure. }\end{array}$ \\
\hline & $\begin{array}{l}\text { - Identification of actions that could be taken in the short term to mitigate the impact of forecasted } \\
\text { floods (e.g. removal of debris accumulated at piers). }\end{array}$ \\
\hline $\begin{array}{l}\text { Impact-based } \\
\text { forecasting }\end{array}$ & $\begin{array}{l}\text { - Paradigm shift from flood hydrograph to impact-based forecasting, so that mitigation measures } \\
\text { can be better planned and justified using cost-benefit criteria. This could contribute to an increased } \\
\text { awareness of the actual risk of bridges and a better acceptance of mitigation measures by affected } \\
\text { communities. }\end{array}$ \\
\hline \multirow[b]{2}{*}{ Data fusion } & $\begin{array}{l}\text {-Evaluation of the metrological effectiveness of sensors for monitoring the effects of floods on } \\
\text { structures. }\end{array}$ \\
\hline & $\begin{array}{l}\text { - Development of approaches for fusing information from numerical models and heterogeneous } \\
\text { sensing systems, providing observations and measurements of different parameters involved in the } \\
\text { risk assessment. These approaches should consider the uncertainty inherent to the models and the } \\
\text { observations, which can be of different nature. They should also be able to propagate these } \\
\text { uncertainties through the various steps contributing to the risk evaluation. }\end{array}$ \\
\hline \multirow{2}{*}{$\begin{array}{l}\text { Value of } \\
\text { information of } \\
\text { data }\end{array}$} & $\begin{array}{l}\text { - Quantification of the benefits, in terms of cost savings to bridge operators and ultimately to } \\
\text { communities, of data and information from sensors. This requires the development of a } \\
\text { methodology for comparing the value of information from systems characterized by different } \\
\text { measured quantities, accuracy, and spatiotemporal resolution. This effort could help to increase } \\
\text { the adoption of sensors for monitoring bridges and rivers by bridge managers and operators. }\end{array}$ \\
\hline & $\begin{array}{l}\text { - Cost-benefit analysis of risk mitigation measures (rip-rap) vis-a-vis bathymetric surveys and } \\
\text { accurate foundation depth evaluations for identifying the most effective scour management } \\
\text { strategies in case of unknown foundation depths. }\end{array}$ \\
\hline
\end{tabular}




\section{References}

Achillopoulou, D. V., Mitoulis, S. A., Argyroudis, S. A., \& Wang, Y. (2020). Monitoring of transport infrastructure exposed to multiple hazards: A roadmap for building resilience. Science of the total environment, 141001.

505 Argyroudis, S. A., Mitoulis, S. A., Winter, M. G., \& Kaynia, A. M. (2019). Fragility of transport assets exposed to multiple hazards: State-of-the-art review toward infrastructural resilience. Reliability Engineering \& System Safety, 191, 106567.

Argyroudis, S. A., Mitoulis, S. A. (2021). Vulnerability of bridges to individual and multiple hazards - floods and earthquakes, Reliability Engineering \& System Safety, 107564.

510 Akay, S. S., Özcan, O., \& Şanlı, F. B. (2021). Quantification and visualization of flood-induced morphological changes in meander structures by UAV-based monitoring. Engineering Science and Technology, an International Journal.

Bandini, F., Lüthi, B., Peña-Haro, S., Borst, C., Liu, J., Karagkiolidou, S., ... \& Bauer-Gottwein, P. (2021). A drone-borne method to jointly estimate discharge and Manning's roughness of natural streams. Water Resources

515 Research, 57(2), e2020WR028266.

Bento, A. M., Gomes, A., Viseu, T., Couto, L., \& Pêgo, J. P. (2020). Risk-based methodology for scour analysis at bridge foundations. Engineering structures, 223, 111115.

Beven, K., Romanowicz, R., Pappenberger, F., Young, P. C., \& Werner, M. (2005, October). The uncertainty cascade in flood forecasting. In Proceedings of the ACTIF meeting on Flood Risk (pp. 1-9).

520 Birch, C. E., Rabb, B. L., Böing, S. J., Shelton, K. L., Lamb, R., Hunter, N. H., Trigg, M. A., Hines, A., Taylor, A. L., Pilling, C., Dale. M. (2021). Enhanced surface water flood forecasts: User-led development and testing. Journal of Flood Risk Management. 14:e12691. https://doi.org/10.1111/jfr3.12691

Breusers, H. N. C., Nicollet, G., \& Shen, H. W. (1977). Local scour around cylindrical piers. Journal of Hydraulic Research, 15(3), 211-252.

525 Breusers, H N C and Raudkivi, A J (1991) "Scouring”. In Davies P.A. (Ed) IAHR Hydraulic structures design manual 2, Balkema, Rotterdam (ISBN: 978-9-06191-983-4)

Briaud, J. L., Gardoni, P., \& Yao, C. (2014). Statistical, risk, and reliability analyses of bridge scour. Journal of Geotechnical and Geoenvironmental Engineering, 140(2), 04013011.

Bridge, P., Bridge, H., Devon, N., Bridge, B., Zealand, N., Bridge, T.,... River, J. (2017). Publication C742

530 manual on scour at bridges and other hydraulic structures (2nd ed., p. 742). London: CIRIA.

Cappello, C., Zonta, D., \& Glišić, B. (2016). Expected utility theory for monitoring-based decision-making. Proceedings of the IEEE, 104(8), 1647-1661.

Chreties, C., Teixeira, L., \& Simarro, G. (2013). Influence of flow conditions on scour hole shape for pier groups. In Proceedings of the Institution of Civil Engineers-Water Management (Vol. 166, No. 3, pp. 111-119). Thomas

535 Telford Ltd.

Cranston, M. D., \& Tavendale, A. C. (2012). Advances in operational flood forecasting in Scotland. In Proceedings of the Institution of Civil Engineers-Water Management (Vol. 165, No. 2, pp. 79-87). Thomas Telford Ltd.

Crotti, G., \& Cigada, A. (2019). Scour at river bridge piers: real-time vulnerability assessment through the

540 continuous monitoring of a bridge over the river Po, Italy. Journal of Civil Structural Health Monitoring, 9(4), 513-528.

Dal Sasso, S. F., Pizarro, A., Pearce, S., Maddock, I., \& Manfreda, S. (2021a). Increasing LSPIV performances by exploiting the seeding distribution index at different spatial scales. Journal of Hydrology, 598, 126438. Dal Sasso, S. F., Pizarro, A., \& Manfreda, S. (2021b). Recent Advancements and Perspectives in UAS-Based 545 Image Velocimetry. Drones, 5(3), 81.

Dikanski, H., Imam, B., \& Hagen-Zanker, A. (2018). Effects of uncertain asset stock data on the assessment of climate change risks: A case study of bridge scour in the UK. Structural Safety, 71, 1-12.

Eltner, A., Bertalan, L., Grundmann, J., Perks, M.T., Lotsari, E., 2021. Hydro-morphological mapping of river reaches using videos captured with unoccupied aerial systems. Earth Surf. Process. Landf. n/a.

550 Ebrahimi M., Kahraman R., Kripakaran P., Djordjevic S., Tabor G., Prodanović D.M. (2017). Scour and hydrodynamic effects of debris blockage at masonry bridges: insights from experimental and numerical modelling. In Proceedings of 37th IAHR world congress, 13-18 August 2017, Kuala Lumpur, Malaysia.

Environment Agency (2021). Peak river flow climate change allowances by management catchment, https://www.gov.uk/government/publications/peak-river-flow-climate-change-allowances-by-managementcatchment, Accessed 20 September 2021. 
Federico, F., Silvagni, G., \& Volpi, F. (2003). Scour vulnerability of river bridge piers. Journal of Geotechnical and Geoenvironmental Engineering, 129(10), 890-899.

Fulton, J. W., Anderson, I. E., Chiu, C. L., Sommer, W., Adams, J. D., Moramarco, T., ... \& Pulli, J. J. (2020). QCam: sUAS-based Doppler radar for measuring river discharge. Remote Sensing, 12(20), 3317.

560 Honfi, D., \& Lange, D. (2015). Structural health monitoring, a tool for improving critical infrastructure resilience. In Proceedings of the 1st Workshop on Quantifying the Value of Structural Health Monitoring COST Action TU1402 (pp. 17-26).

Giordano, P. F., Prendergast, L. J., \& Limongelli, M. P. (2020). A framework for assessing the value of information for health monitoring of scoured bridges. Journal of Civil Structural Health Monitoring, 10(3), 485496.

Hossain, M. S., Khan, M. S., Hossain, J., Kibria, G., \& Taufiq, T. (2013). Evaluation of unknown foundation depth using different NDT methods. Journal of performance of constructed facilities, 27(2), 209-214.

Hulet, K. M., Smith, C. C., \& Gilbert, M. (2006). Load-carrying capacity of flooded masonry arch bridges. In Proceedings of the Institution of Civil Engineers-Bridge Engineering (Vol. 159, No. 3, pp. 97-103). Thomas

570 Telford Ltd

Jaroszweski, D., Wood, R., and Chapman, L. (2021) Infrastructure. In: The Third UK Climate Change Risk Assessment Technical Report. [Betts, R.A., Haward, A.B., Pearson, K.V. (eds)] Prepared for the Climate Change Committee, London.

Jeong, Y., Kim, W. S., Lee, I., \& Lee, J. (2018). Bridge inspection practices and bridge management programs in

575 China, Japan, Korea, and U.S. Journal of Structural Integrity and Maintenance, 3(2), 126-135.

Johnson, P. A., Clopper, P. E., Zevenbergen, L. W., \& Lagasse, P. F. (2015). Quantifying uncertainty and reliability in bridge scour estimations. Journal of Hydraulic Engineering, 141(7), 04015013.

Kim, H., Sim, S. H., Lee, J., Lee, Y. J., \& Kim, J. M. (2017). Flood fragility analysis for bridges with multiple failure modes. Advances in Mechanical Engineering, 9(3), 1687814017696415.

580 Kirby AM, Roca M, Kitchen A, Escarameia M, Chesterton OJ (2015) Manual on scour at bridges and other hydraulic structures, second edition. C742, CIRIA, London. Retrieved from: www.ciria.org.

Kitchen A, Roca M, Kirby AM, Escarameia M (2021) Manual on scour at bridges and other hydraulic structures - supplementary guide. SP171, CIRIA, London. Retrieved from: www.ciria.org.

Komma, J., Reszler, C., Blöschl, G., \& Haiden, T. (2007). Ensemble prediction of floods-catchment non-linearity and forecast probabilities. Natural Hazards and Earth System Sciences, 7(4), 431-444.

Koursari, E., \& Wallace, S. (2020, March). Infrastructure scour management: a case study for A68 Galadean Bridge, UK. In Proceedings of the Institution of Civil Engineers-Bridge Engineering (Vol. 173, No. 1, pp. 42-49). Thomas Telford Ltd.

Lamb, R., Aspinall, W., Odbert, H., \& Wagener, T. (2017). Vulnerability of bridges to scour: insights from an

590 international expert elicitation workshop. Natural Hazards and Earth System Sciences, 17(8), 1393-1409.

Lamb, R., Garside, P., Pant, R., \& Hall, J. W. (2019). A probabilistic model of the economic risk to Britain's railway network from bridge scour during floods. Risk Analysis, 39(11), 2457-2478.

Lai, Y. G., \& Greimann, B. P. (2010). Predicting contraction scour with a two-dimensional depth-averaged model. Journal of Hydraulic Research, 48(3), 383-387.

595 Le Coz, J., Hauet, A., Pierrefeu, G., Dramais, G., \& Camenen, B. (2010). Performance of image-based velocimetry (LSPIV) applied to flash-flood discharge measurements in Mediterranean rivers. Journal of hydrology, 394(1-2), $42-52$.

Liang, F., Wang, C., \& Yu, X. (2019). Performance of existing methods for estimation and mitigation of local scour around bridges: Case studies. Journal of Performance of Constructed Facilities, 33(6), 04019060.

600 Link, O., Castillo, C., Pizarro, A., Rojas, A., Ettmer, B., Escauriaza, C., \& Manfreda, S. (2017). A model of bridge pier scour during flood waves. Journal of Hydraulic Research, 55(3), 310-323.

Link, O., García, M., Pizarro, A., Alcayaga, H., \& Palma, S. (2020). Local scour and sediment deposition at bridge piers during floods. Journal of Hydraulic Engineering, 146(3), 04020003.

Liu, L., Frangopol, D. M., Mondoro, A., \& Yang, D. Y. (2018). Sustainability-informed bridge ranking under

605 scour based on transportation network performance and multiattribute utility. Journal of Bridge Engineering, 23(10), 04018082.

Maddison, B. (2012). Scour failure of bridges. Proceedings of the Institution of Civil Engineers-Forensic Engineering, 165(1), 39-52.

Maroni, A., Tubaldi, E., Ferguson, N., Tarantino, A., McDonald, H., \& Zonta, D. (2020). Electromagnetic sensors 
Maroni (2020). An SHM-based decision support system for risk management of bridge scour. PhD Thesis. University of Strathclyde.

Maroni, A., Tubaldi, E., Val, D. V., McDonald, H., \& Zonta, D. (2020). Using Bayesian networks for the assessment of underwater scour for road and railway bridges. Structural Health Monitoring, 1475921720956579.

615 Mathews, R., \& Hardman, M. (2017). Lessons learnt from the December 2015 flood event in Cumbria, UK Proceedings of the Institution of Civil Engineers-Forensic Engineering, 170(4), 165-178.

Melville, B. W., \& Sutherland, A. J. (1988). Design method for local scour at bridge piers. Journal of Hydraulic Engineering, 114(10), 1210-1226.

Merz, B., Kuhlicke, C., Kunz, M., Pittore, M., Babeyko, A., Bresch, D. N., ... \& Wurpts, A. (2020). Impact forecasting to support emergency management of natural hazards. Reviews of geophysics, 58(4), e2020RG000704. Middleton, C. (2004). Bridge management and assessment in the UK. In Austroads bridge conference, 5TH, 2004, Hobart, Tasmania, Australia (No. AP-G79/04).

Mitoulis, S. A., Argyroudis, S. A., Loli, M., \& Imam, B. (2021). Restoration models for quantifying flood resilience of bridges. Engineering Structures, 238, 112180.

625 Mitoulis, S. A., \& Argyroudis, S. A. (2021). Restoration models of flood resilient bridges: Survey data. Data in brief, 36, 107088

Mondoro, A., Frangopol, D. M. (2018). Risk-based cost-benefit analysis for the retrofit of bridges exposed to extreme hydrologic events considering multiple failure modes. Engineering Structures 159: 310-319.

Montanari, M., Hostache, R., Matgen, P., Schumann, G., Pfister, L., \& Hoffmann, L. (2009). Calibration and

630 sequential updating of a coupled hydrologic-hydraulic model using remote sensing-derived water stages. Hydrology and Earth System Sciences, 13(3), 367-380.

Moore, M. et al. (2001). FHWA-RD-01-020 Reliability of Visual Inspection for Highway Bridges, Volume I; Final Report, West Virginia, USA: Federal Highway Administration.

635 Master Thesis. TU Delft, Netherlands.

Oudenbroek, K., Naderi, N., Bricker, J. D., Yang, Y., Van der Veen, C., Uijttewaal, W., ... \& Jonkman, S. N. (2018). Hydrodynamic and debris-damming failure of bridge decks and piers in steady flow. Geosciences, 8(11), 409.

640 accumulation of woody debris at bridge piers. Journal of Hydraulic Engineering, 146(6).

Panici, D., G. de Almeida (2018). Formation, growth, and failure of debris jams at bridge piers. Water Resources Research, 54(9), 6226-6241.

Park, C. W., Park, H. I., \& Cho, Y. K. (2017). Evaluation of the applicability of pier local scour formulae using laboratory and field data. Marine Georesources \& Geotechnology, 35(1), 1-7.

645 Pizarro, A., Ettmer, B., Manfreda, S., Rojas, A., \& Link, O. (2017). Dimensionless effective flow work for estimation of pier scour caused by flood waves. Journal of Hydraulic Engineering, 143(7), 06017006.

Pizarro, A., Samela, C., Fiorentino, M., Link, O., \& Manfreda, S. (2017). BRISENT: an entropy-based model for bridge-pier scour estimation under complex hydraulic scenarios. Water, 9(11), 889.

Pizarro, A., Dal Sasso, S. F., \& Manfreda, S. (2020). Refining image-velocimetry performances for streamflow monitoring: Seeding metrics to errors minimization. Hydrological Processes, 34(25), 5167-5175.

Pizarro, A., \& Tubaldi, E. (2019). Quantification of modelling uncertainties in bridge scour risk assessment under multiple flood events. Geosciences, $9(10), 445$.

Pizarro, A., Manfreda, S., \& Tubaldi, E. (2020). The science behind scour at bridge foundations: A review. Water, 12(2), 374.

655 Porter K. (2015) Beginner's Guide to Fragility, Vulnerability, and Risk. In: Beer M., Kougioumtzoglou I.A., Patelli E., Au SK. (eds) Encyclopedia of Earthquake Engineering. Springer, Berlin, Heidelberg. https://doi.org/10.1007/978-3-642-35344-4_256

Prendergast, L. J., \& Gavin, K. (2014). A review of bridge scour monitoring techniques. Journal of Rock Mechanics and Geotechnical Engineering, 6(2), 138-149.

660 Prendergast, LJ., Limongelli M.P, Ademovic N., Anžlin A., Gavin K., Zanini M.. Structural health monitoring for performance assessment of bridges under flooding and seismic actions. Structural Engineering International 28, no. 3 (2018): 296-307.

Pregnolato, M. (2019). Bridge safety is not for granted-A novel approach to bridge management. Engineering Structures, 196, 109193.

665 Rivertrack. http://www.rivertrack.org/ 
Qi, M., Li, J., \& Chen, Q. (2018). Applicability analysis of pier-scour equations in the field: Error analysis by rationalizing measurement data. Journal of Hydraulic Engineering, 144(8), 04018050.

Richardson, E.V.; Davis, S.R. Evaluating Scour at Bridges; Hydraulic Engineering Circular (HEC) No. 18; U.S. Department of Transportation: Washington, DC, USA, 2001.

670 Rivertrack. Flood Alerting for Resilient Communities. http://www.rivertrack.org/

Roca, M., \& Whitehouse, R. (2012). Scour risk assessment at river crossings. Proceedings of ICSE6 Paris, August 27-31, $1-10$. Retrieved from https://eprints.hrwallingford.com/887/1/HRPP528 Scour risk assessment at river_crossings.pdf.

Sasidharan, M., Parlikad, A. K., \& Schooling, J. (2021). Risk-informed asset management to tackle scouring on bridges across transport networks. Structure and Infrastructure Engineering, 1-17.

Shahriar, A. R., Ortiz, A. C., Montoya, B. M., \& Gabr, M. A. (2021). Bridge Pier Scour: An overview of factors affecting the phenomenon and comparative evaluation of selected models. Transportation Geotechnics, 100549. Sheppard, D. M., Melville, B., \& Demir, H. (2014). Evaluation of existing equations for local scour at bridge piers. Journal of Hydraulic Engineering, 140(1), 14-23.

680 Scozzese, F., Ragni, L., Tubaldi, E., \& Gara, F. (2019). Modal properties variation and collapse assessment of masonry arch bridges under scour action. Engineering Structures, 199, 109665.

Schmocker, L., \& Hager, W. H. (2011). Probability of drift blockage at bridge decks. Journal of Hydraulic Engineering, 137(4), 470-479.

Speight, L. J., Cranston, M. D., White, C. J., \& Kelly, L. (2021). Operational and emerging capabilities for surface water flood forecasting. Wiley Interdisciplinary Reviews: Water, 8(3), e1517.

Tanasić, N., Ilić, V., \& Hajdin, R. (2013). Vulnerability assessment of bridges exposed to scour. Transportation research record, 2360(1), 36-44.

Tanasić, N., \& Hajdin, R. (2017). Performance indicators for bridges exposed to a flooding hazard. In Proceedings of the Joint COST TU 1402-COST TU 1406-IABSE WC1 Workshop in Zagreb.

690 Thacker, S., Barr, S., Pant, R., Hall, J.W. and Alderson, D. (2017). Geographic Hotspots of Critical National Infrastructure. Risk Analysis, 37: 2490-2505. https://doi.org/10.1111/risa.12840

Transport Scotland. Scour Management Strategy and Flood Emergency Plan.

Triantaphyllou, E. (2000). Multi-criteria decision making methods: A comparative study, Springer.

Tubaldi, E., Macorini, L., \& Izzuddin, B. A. (2018). Three-dimensional mesoscale modelling of multi-span 695 masonry arch bridges subjected to scour. Engineering Structures, 165, 486-500.

Tubaldi, E., Macorini, L., Izzuddin, B. A., Manes, C., \& Laio, F. (2017). A framework for probabilistic assessment of clear-water scour around bridge piers. Structural safety, 69, 11-22.

Tubaldi, E., Macorini, L., \& Izzuddin, B. (2017). Flood risk assessment of masonry arch bridges. In 2nd International Conference on Uncertainty Quantification in Computational Sciences and Engineering, $700 \operatorname{UNCECOMP}($ pp. 15-17).

Tubaldi, E., Maroni, A., Ferguson, N. and Zonta, D. (2020) Evaluating the benefit of structural health monitoring for improving bridge resilience against scour. Deliverable D1 - Report on critical review of alternative techniques for bridge scour monitoring. Documentation. National Centre for Resilience. Retrieved from: https://sway.office.com/paZdmLnyF7wb5Zbh?ref=Link.

705 Tubaldi, E., Maroni, A., Ferguson, N. and Zonta, D. (2020) Evaluating the benefit of structural health monitoring for improving bridge resilience against scour. Deliverable D2 - Framework for sensor data fusion. Documentation. National Centre for Resilience.

Tubaldi, E., Ozer, E., Douglas, J., \& Gehl, P. (2021). Examining the contribution of near real-time data for rapid seismic loss assessment of structures. Structural Health Monitoring, 1475921721996218.

710 Tucker, S. E., Briaud, J. L., Hurlebaus, S., Everett, M. E., \& Arjwech, R. (2015). Electrical resistivity and induced polarization imaging for unknown bridge foundations. Journal of Geotechnical and Geoenvironmental Engineering, 141(5), 04015008.

Van Leeuwen, Z.; Lamb, R. Flood and scour related failure incidents at railway assets between 1846 and 2013; 542 2014;

715 Vardanega, P. J., Gavriel, G., \& Pregnolato, M. (2021). Assessing the suitability of bridge-scour-monitoring devices. Proceedings of the Institution of Civil Engineers-Forensic Engineering, Published online, Retrieved from: https://doi.org/10.1680/jfoen.20.00022

Wagenaar, D., Curran, A., Balbi, M., Bhardwaj, A., Soden, R., Hartato, E., ... \& Lallemant, D. (2020). Invited perspectives: How machine learning will change flood risk and impact assessment. Natural Hazards and Earth System Sciences, 20(4), 1149-1161. 
Wang, C., Yu, X., Liang, F. (2017). Comparison and estimation of the local scour depth around pile groups and wide piers. In Geotechnical Frontiers; Brandon, T.L., Valentine, R.J., Eds.; ASCE: Reston, VA, USA, 2017; pp. $11-19$.

Wetterhall, F., \& Giuseppe, F. D. (2018). The benefit of seamless forecasts for hydrological predictions over Europe. Hydrology and Earth System Sciences, 22(6), 3409-3420.

White, C. J., Carlsen, H., Robertson, A. W., Klein, R. J., Lazo, J. K., Kumar, A., ... \& Zebiak, S. E. (2017). Potential applications of subseasonal-to-seasonal (S2S) predictions. Meteorological applications, 24(3), 315-325. Wiggins, D., Mudd, K., \& Healey, M. (2018). Rehabilitation of Brougham Castle Bridge, UK. In Proceedings of the Institution of Civil Engineers-Engineering History and Heritage, 172(1), 7-18.

730 Ye, C., Butler, L., Calka, B., Iangurazov, M., Lu, Q., Gregory, A., ... \& Middleton, C. (2019). A digital twin of bridges for structural health monitoring. Structural Health Monitoring 2019: Enabling Intelligent Life-Cycle Health Management for Industry Internet of Things (IIOT) - Proceedings of the 12th International Workshop on Structural Health Monitoring, 1.

Yu, W., Nakakita, E., Kim, S., \& Yamaguchi, K. (2016). Impact assessment of uncertainty propagation of ensemble NWP rainfall to flood forecasting with catchment scale. Advances in Meteorology, 2016.

Zampieri, P., Zanini, M. A., Faleschini, F., Hofer, L., \& Pellegrino, C. (2017). Failure analysis of masonry arch bridges subject to local pier scour. Engineering Failure Analysis, 79, 371-384.

\section{Code and data availability}

740 Literature used to inform this invited perspective is set out in the reference list.

\section{Author contributions}

All authors participated to the workshop or subsequent meetings underpinning this invited perspective. Enrico Tubaldi wrote the manuscript with contributions from all co-authors. Significant contribution was given by Gustavo de Almeida on section 2.1, Alonso Pizarro on section 2.2, Rob Lamb on section 2.3, Stergios Mitoulis on section 2.4, Eftychia Koursari on section 2.5, Christopher White and Jim Brown on section 2.6, Richard Mathews on sections 2.2, 2.3 and 2.6. All the coauthors reviewed the paper and provided additional perspectives that enhanced the final version.

\section{Competing interests}

The authors declare that they have no conflict of interest. 